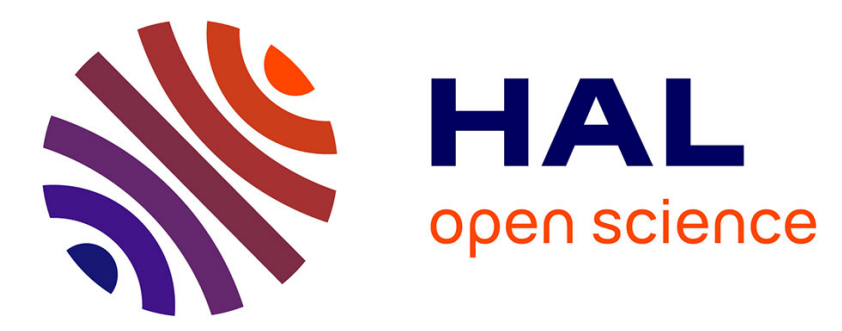

\title{
Sensory perception of textural properties of cosmetic Pickering emulsions
}

Daria Terescenco, Nicolas Hucher, Celine Picard, Géraldine Savary

\section{To cite this version:}

Daria Terescenco, Nicolas Hucher, Celine Picard, Géraldine Savary. Sensory perception of textural properties of cosmetic Pickering emulsions. International Journal of Cosmetic Science, 2020, 42 (2), pp.198-207. 10.1111/ics.12604 . hal-02612551

HAL Id: hal-02612551

https://hal-normandie-univ.archives-ouvertes.fr/hal-02612551

Submitted on 19 May 2020

HAL is a multi-disciplinary open access archive for the deposit and dissemination of scientific research documents, whether they are published or not. The documents may come from teaching and research institutions in France or abroad, or from public or private research centers.
L'archive ouverte pluridisciplinaire HAL, est destinée au dépôt et à la diffusion de documents scientifiques de niveau recherche, publiés ou non, émanant des établissements d'enseignement et de recherche français ou étrangers, des laboratoires publics ou privés. 


\title{
SENSORY PERCEPTION OF TEXTURAL PROPERTIES OF COSMETIC PICKERING EMULSIONS
}

\author{
Daria Terescenco ${ }^{1}$, Nicolas Hucher ${ }^{1}$, Celine Picard ${ }^{1}$, Geraldine Savary*1 \\ ${ }^{1}$ Normandie Univ, UNIHAVRE, FR 3038 CNRS, URCOM, 76600 Le Havre, France \\ nicolas.hucher@univ-lehavre.fr \\ celine.picard@univ-lehavre.fr \\ geraldine.savary@univ-lehavre.fr \\ daria.terescenco@univ-lehavre.fr \\ * Corresponding author. \\ TEL: +33232743911
}

\section{KEYWORDS}

Emulsion

Formulation/stability

Delivery/vectorisation/penetration

Pickering

Particle stabilization

Sensory analysis

\section{ABSTRACT}

OBJECTIVE: The increasing interest for the Pickering emulsions is based on the possibility to replace classical emulsifiers by the solid particles. This approach is extremely attractive for the cosmetic field. But, the main difficulty is to obtain stable emulsions with appreciable skin feel. However, there is no information about the texture of such systems. The aim of this study is to formulate and describe the textural properties of cosmetic Pickering emulsions compared to conventional systems.

METHODS: Three metal oxides were selected: titanium dioxide, zinc oxide and silicon dioxide, able to form stable and totally emulsified systems. A conventional emulsifier was used to formulate the emulsion of reference. Finally, the mixture of two emulsifying systems, combining both, surfactant and particles, was also studied. Then, a sensory panel was asked to quantify the intensities of the perception of the seven discriminating attributes.

RESULTS: Each particle brought its properties to the textural perception of the emulsion. $\mathrm{TiO}_{2}$ particles ensured the whitening effect of the emulsions, $\mathrm{SiO}_{2}$ provided the screech residue, while $\mathrm{ZnO}$ gave intermediate results. The conventional surfactant was perceived as glossy, greasy and more difficult to spread. The particle/surfactant mixtures gave mostly in-between results.

CONCLUSIONS: The study shows that the sensory profile of Pickering emulsions is indirectly and directly governed by the particle properties used for the emulsion stabilisation: indirectly, through affecting the 
emulsion orientation (oil in water or water in oil), the droplet organisation and viscosity, and directly, through the particle perception on the skin surface.

\section{INTRODUCTION}

The main interest of Pickering emulsions is the possibility to replace conventional emulsifiers with solid particles [1,2]. An important number of solid particles, of different characteristics, were studied in the literature able to stabilise the interface of two non-miscible liquids: clay, chitosan, cyclodextrin [3], starch [4], iron oxides [5], titanium dioxide [6], silica [7-10], etc.

Pickering emulsions are considered as stable when droplets are completely stable to coalescence and their size does not evolve over time [11]. Although all these emulsions are completely stable to coalescence, oil external (W/O) Pickering emulsions can sediment and water external $(0 / W)$ ones can cream under gravity [12]. This two processes, considered as destabilisation mechanisms for classical emulsions [13], are accepted by the authors in case of Pickering emulsions. In fact, they do not induce the droplet evolution, but only the macroscopic droplet reorganisation. For example, Binks and Lumsdon [14] made the difference between the creaming of an $\mathrm{O} / \mathrm{W}$ emulsion and the coalescence: "The stability of o/w emulsions to creaming was assessed by monitoring the increase with time of the position of the clear water (serum)-emulsion interface, whereas the coalescence extent was estimated from the movement of the oil-emulsion boundary." In this case, the final system, considered stable over time, is finally not homogenous, due to the gradual distribution of the droplets in the continuous phase. Consequently, the macroscopic study of such a system becomes difficult, the separated phase should be avoided when the sample is collected [15]. Consequently, in order to use this type of emulsions in food, pharmaceutical and cosmetic fields, one should also guarantee the emulsions total emulsification.

Pickering emulsions, due to their physical stability [16], can be potentially used as delivery systems of actives in biomedical [17] and food applications [18,19], or pharmaceutics and cosmetics [20,21], namely for alltrans-retinol [9,22] or caffeine [23] skin delivery.

The sensory analysis is essential when developing products with further applicative interest. It was largely described for cosmetic raw materials and emulsions [24-29], but only a few results were given for Pickering emulsions. Marto et al. [4] evaluated the textural properties of the Starch-based emulsions using a simple sensory questionnaire in which the basic characteristics, i.e. texture and skin feel, were evaluated by the volunteers. In their work, the authors were mostly focused on the oil phase-type in starch-stabilised emulsions and their results did not discriminate the products according to the analysed parameters. Marku et al. [21] developed Pickering emulsions stabilised by octenyl succinic anhydride-modified quinoa starch containing three different oil phases. A small panel of volunteers was recruited to scale the intensities of the visual appearance of the formulation, the feel of the cream (thick, sticky, slippery, watery), the skin feel during and after absorption. The results of this study gave an interesting perspective of the oil phase impact on the sensory perception but did not explain the impact of the particle on the studied parameters. Besides, only usual attributes for the cosmetic emulsions were selected, without analysing the perception brought by the starch particles.

Considering Pickering emulsions stabilised with inorganic particles, there is until recently no information in the literature about their textural properties [30].

The authors developing such systems with silica particles are more focused on the emulsions capacity to play the role of the vehicles for the active ingredients and their diffusion in the Stratum Corneum [9,23,31] with no information about the sensory profile of the formulations. Other inorganic particles of the great interest for 
the formulation of the Pickering emulsions are titanium dioxide and zinc oxide. Usually, $\mathrm{TiO}_{2}$ and $\mathrm{ZnO}$ are used in sunscreens for the sensitive skin and for the sunscreens with high sun protection factor [32], but they can also play the role of both, emulsion stabiliser and photo protector, by using an important quantity of physical filters (35\%) of titanium dioxide and/or zinc oxide type combined with melatonin [33] or green coffee oil $[34,35]$. In our recent study, we described the microscopic, macroscopic and applicative proprieties of the $\mathrm{TiO}_{2}$ stabilised system from an instrumental point of view [30].

Taking into account the applicative interest of the Pickering sunscreen emulsions, the sensory description of such systems is awaited, but there is still a lack in the literature on this point [36].

The novelty of our study lies in the development of an original methodology to characterise the sensory properties of the Pickering emulsions. First, three inorganic solid particles, able to stabilise the interface and to form totally emulsified systems, were selected: silicon dioxide $\left(\mathrm{SiO}_{2}\right)$, zinc oxide $(\mathrm{ZnO})$ and titanium dioxide $\left(\mathrm{TiO}_{2}\right)$. Due to their physicochemical properties, the particles were able to form emulsions, which will be described further. To bring new elements of comprehension of how the Pickering emulsions are perceived on the human skin, we completed the studied systems with two new formulations: reference emulsions, which were formulated with a conventional Steareth-2/21 surfactant and, finally, emulsions combining both emulsifying systems were also developed and investigated.

\section{MATERIALS AND METHODS}

\section{MATERIALS}

The raw materials used in this study were kindly provided by the suppliers listed in Table I. The selected raw materials were of cosmetic grade considering the further interest of emulsions topical application.

The surfactant chosen for this study is a combination of two ethoxylated ethers: Steareth-2 is a polyoxyethylene (2) stearyl ether and the Steareth-21 a polyoxyethylene (21) stearyl ether [37].

Table I. INCI, CAS, trade name and the supplier of raw materials

\begin{tabular}{|c|c|c|c|}
\hline INCI & CAS & Trade name & Supplier \\
\hline Titanium Dioxide, Silica, Cetyl phosphate & $\begin{array}{l}\text { 13463-67-7; 7631-86-9; } \\
3539-43-3\end{array}$ & Eusolex® T-Easy & Merck \\
\hline Zinc Oxide, Jojoba Esters & 1314-13-2; 61789-91-1 & ZnO-750-NJE7 & Kobo \\
\hline Silica cetyl silylate & $199876-45-4$ & Aerosil@ & \\
\hline Steareth-2 & $9005-00-9$ & Massocare® S2 & Massó \\
\hline Steareth-21 & $9005-00-9$ & Massocare ${ }^{\circledR}$ S21 & Massó \\
\hline Caprylic capric triglycerides (CCT) & $73398-61-5$ & $\begin{array}{l}\text { Triglycerides } \\
\text { C8C10 55/45 } \\
\end{array}$ & $\begin{array}{l}\text { Stéarinerie } \\
\text { Dubois }\end{array}$ \\
\hline \multicolumn{4}{|l|}{ Deionized Water } \\
\hline $\begin{array}{l}\text { Phenoxyethanol and Methylparaben and } \\
\text { Ethylparaben and Propylparaben and } \\
\text { Butylparaben }\end{array}$ & $\begin{array}{l}122-99-6 ; 99-76-3 ; 120- \\
47-8 ; 94-13-3 ; 94-26-8\end{array}$ & Sepicide HB & Seppic \\
\hline
\end{tabular}

\section{SYSTEMS AND CHARACTERISATION}

Three solid particles were selected for the emulsion stabilisation: titanium dioxide $\mathrm{TiO}_{2}$ (at $\mathbf{4 \%}$ and $\mathbf{1 0 \%}$ ), zinc oxide $\mathrm{ZnO}$ (at $\mathbf{1 0 \%}$ ) and silica $\mathrm{SiO}_{2}$ (at $\mathbf{4 \%}$ ). Then, a conventional surfactant, solid at ambient temperature, was used for the formulation of the reference emulsion (at $\mathbf{4 \%}$ and $\mathbf{1 0 \%}$ ). Classical emulsifier mixture of non-ionic surfactants Steareth-2/Steareth-21, often used for topical applications, is well known for 
its stabilizing property [38] and was already used for previous studies of the nanoparticle-based emulsions $[39,40]$.

To explore the effect of the solid stabiliser versus a classic emulsifier, several emulsions were formulated as a mixture of both stabilising systems (at $\mathbf{2 \%}+\mathbf{2 \%}$ and $\mathbf{5 \% + 5 \%}$ of the mixture). The composition of the nine emulsions formulated for this study is presented in Table II. The oil/water for each system ratio was fixed at $40 / 60$ and a preservative was introduced to avoid bacterial proliferation.

Table II. Emulsion code and composition of the stabilizing system/oil phase/water phase for each of the nine studied emulsions.

\begin{tabular}{|c|c|c|c|c|c|c|c|}
\hline \multirow{2}{*}{$\begin{array}{c}\text { Emulsion } \\
\text { code }\end{array}$} & \multicolumn{4}{|c|}{ Stabilizing system } & \multirow{2}{*}{$\begin{array}{c}\text { Oil phase } \\
\text { Caprylic capric } \\
\text { Triglycerides } \\
(\%)\end{array}$} & \multirow{2}{*}{$\begin{array}{c}\text { Water } \\
\text { phase }\end{array}$} & \multirow[b]{2}{*}{$\begin{array}{c}\text { Preservative } \\
\text { (\%) }\end{array}$} \\
\hline & $\begin{array}{l}\text { Zn0 } \\
(\%)\end{array}$ & $\begin{array}{l}\mathrm{TiO}_{2} \\
(\%)\end{array}$ & $\begin{array}{l}\mathrm{SiO}_{2} \\
(\%)\end{array}$ & $\begin{array}{l}\text { Steareth- } \\
2 / 21(\%)\end{array}$ & & & \\
\hline Zn010 & 10 & - & - & - & 35.6 & 53.4 & 1 \\
\hline Zn05St5 & 5 & - & - & 5 & 35.6 & 53.4 & 1 \\
\hline $\mathrm{TiO}_{2} 4$ & - & 4 & - & - & 38 & 57 & 1 \\
\hline $\mathrm{TiO}_{2} 10$ & - & 10 & - & - & 35.6 & 53.4 & 1 \\
\hline $\mathrm{TiO}_{2} 5 \mathrm{St} 5$ & - & 5 & - & 5 & 35.6 & 53.4 & 1 \\
\hline $\mathrm{SiO}_{2} 4$ & - & - & 4 & - & 38 & 57 & 1 \\
\hline $\mathrm{SiO}_{2} 2 \mathrm{St} 2$ & - & - & 2 & 2 & 38 & 57 & 1 \\
\hline St4 & - & - & - & 4 & 38 & 57 & 1 \\
\hline St10 & - & - & - & 10 & 35.6 & 53.4 & 1 \\
\hline
\end{tabular}

\section{EMULSIONS FORMULATION}

The formulation process of the nine emulsions is strongly dependent on the emulsifying system type. In the case of the conventional emulsifier, the heating step is necessary before the emulsifying step. The physicochemical properties of the solid particles should also be taken into account to choose an adapted method of the pre-dispersion step in the suitable oil or water phase. All the systems were formulated at 200 $\mathrm{mL}$ to ensure the instrumental and the sensory analysis.

$\mathrm{TiO}_{2} 10 / \mathrm{SiO}_{2} 4 / \mathrm{ZnO10}$ emulsion - the particles were first pre-dispersed in the water phase for $\mathrm{TiO}_{2}$ and $\mathrm{SiO}_{2}$, and in the oil phase for $\mathrm{ZnO}$. Next, the internal phase is added to the continuous phase during 30 seconds under vigorous stirring (11000 rpm) using a rotor-stator T25 digital ultra-turrax (IKA, Freiburg, Germany) equipped with the dispersing head S25N-25F. Then, the homogenization is continued for 1.30 minutes to form an emulsion. Finally, after adding the preservative, the mixture was put under stirring (Turbotest, radial flow turbine of $55 \mathrm{~mm}$ diameter, VMI Raynerie) at $500 \mathrm{rpm}$ for 15 minutes. All the emulsion formulation process was carried out at the ambient temperature.

St10 / St4 emulsion- the oil phase containing the emulsifier was heated up to $80^{\circ} \mathrm{C}$ under mechanical stirring (400 rpm), as well as the water phase. Then, as for the previous system, the oil phase was added to the water for 30 seconds and the homogenisation was continued for 1.30 minutes at $11000 \mathrm{rpm}$. The formulation was left cooling down to $30^{\circ} \mathrm{C}$ under stirring (Turbotest, radial flow turbine of $55 \mathrm{~mm}$ diameter, VMI Raynerie) at $400 \mathrm{rpm}$. Next, the preservative was added and the emulsion was left under the same stirring for more 15 minutes.

$\mathrm{TiO}_{2} 5 \mathrm{St5} / \mathrm{SiO}_{2} 2 \mathrm{St2}$ / Zn05St5 emulsion was prepared using both protocols - particles were pre-dispersed in the water phase for $\mathrm{TiO}_{2}$ and $\mathrm{SiO}_{2}$, and in the oil phase for $\mathrm{ZnO}$ and then heated up to $80^{\circ} \mathrm{C}$, the surfactant is mixed with the oil phase and also heated up to $80^{\circ} \mathrm{C}$. Next steps are identic to the previous emulsions. 
Once prepared, the mixtures were split into three samples, stored at $4{ }^{\circ} \mathrm{C}, 40^{\circ} \mathrm{C}$ and ambient temperature, respectively, for stability monitoring. Before any sensory analysis, the stability of the systems over time (D+7, D+15, D+30) was checked by classical techniques: microscopy, particle size analysis, rheological studies. This approach was necessary to ensure that the properties of the system will not evolve during the sensory study.

\section{EMULSIONS ASPECT}

\section{Microscopy}

The emulsions microstructure was observed using an optical microscope (Leica DMLP microscope) equipped with a digital camera at a magnification of $\mathrm{x} 100$ under the bright field at the ambient temperature of storage at D30. Leica IM 1000 software was used to analyse the micrographs.

\section{Droplet size distribution}

The emulsion droplets size were measured by static light scattering (SLS) using a laser diffraction particle size analyser SALD-7500 nano (Shimadzu Co., Ltd, Japan) equipped with a violet semiconductor laser (405 nm). The emulsions, except the $\mathrm{ZnO}$ containing emulsions, were diluted with deionized water to achieve the absorption parameter equal to 0.2 . For the $\mathrm{ZnO}$ containing, inverse water in oil emulsions, the dilution was done with the oil phase. Considering the important chemical inhomogeneity of the medium (presence of the particles and their agglomerations besides to the oil phase droplets), and to get rid of the optical properties of all of them, the Fraunhofer theory was used. The droplets median values $\mathrm{D}[4,3]$ were acquired, representing the size in microns that splits the distribution with half above and half below this diameter.

\section{Rheology}

Rheological tests were performed using a controlled stress rheometer (HR2, TA instruments). All the measurements were carried out in duplicate at $25^{\circ} \mathrm{C}$. The solvent trap was used to prevent sample drying. Once loaded, the samples were left at rest for two minutes prior to any measurement. Samples were analysed once and then changed prior to further analysis. Flow curves were obtained by recording shear stress and viscosity values at increasing shear rates ranging from 0,001 to final $50001 / \mathrm{s}$ (continuous ramp, logarithmic mode) for 300s. $60 \mathrm{~mm}$ aluminium parallel-plate device was used for the test and the gap was fixed at $200 \mu \mathrm{m}$.

\section{SENSORY ANALYSIS}

The recruited panel was composed of 23 volunteers aged from 22 to 45 years old and selected among Le Havre University. Subjects were voluntary and gave all their written consent to participate in the study. The study and all protocols were approved by the Ethics Committee from Le Havre University. Prior to any sensory analysis, a microbiological test was performed (ACM,Bellegarde, France) to make sure that each product was in accordance with the cosmetic criteria for bacterial contamination ( $<100 \mathrm{UFC} / \mathrm{g}$ or $/ \mathrm{ml}$ ) for both the search of aerophilic mesophilic bacteria [41] and the enumeration of yeasts and molds [42]. All the samples presented $<10 \mathrm{UFC} / \mathrm{ml}$, so suitable for the sensory analysis. First, two training sessions were organized to acquire the definition of each attribute, the evaluation procedure, the rating scale (from 0 to 9 ) and the commercial references (Table III). The used references: A - deionized water, B - Vichy "Ideal soleil" Gentle milk for children SPF 50; C - URIAGE “Bariesun" Mineral cream, SPF30. Then, each of the nine products was evaluated twice in the same conditions in individual booths.

Table III. Application phase, studied attributes, their definitions and the reference scales used for the sensory analysis

\begin{tabular}{lllccc}
\hline Phase & Attribute & Definition & A & B & C \\
\hline Rub-out & Non-aqueous & Quantity of water perceived during application & 0 & 5 & 8 \\
Rub-out & Difficulty of Spreading & Force required to move product over skin & 0 & 5 & 8 \\
\hline
\end{tabular}




\begin{tabular}{llllll}
\hline Rub-out & Whitening effect & Quantity and intensity of white colour covering the skin & 0 & 5 & 8 \\
After feel & Film whiteness & Quantity and intensity of white colour covering the skin & 0 & 5 & 8 \\
After feel & Film glossiness & Amount of reflected light from the film & 0 & 4 & 6 \\
After feel & Greasiness & Quantity of thick, rich, unctuous residue on the skin & 0 & 6 & 8 \\
After feel & Screech residue & Friction sound, the stick-slip character of the residue & 0 & 1 & 3 \\
\hline
\end{tabular}

Each assessor respected a precise protocol: "Wash your hands and your forearms with a hydroalcoholic gel. Place $40 \mu \mathrm{L}$ of the product in the middle of the circle $(\varnothing=5 \mathrm{~cm})$ drawn on the inner surface of the forearm. Spread the product within the circle using forefinger, by making one circular motion per the sound signal of the metronome (corresponding to 90 beeps/minute). Evaluate the Non-aqueous property between the $1^{\text {st }}$ and the $5^{\text {th }}$ circle. Continue the circular motions and evaluate the Difficulty of spreading between the $10^{\text {th }}$ and the $20^{\text {th }}$ circle. Evaluate the Whitening effect of the product on the skin between the $20^{\text {th }}$ and the $30^{\text {th }}$ circle outside a direct source of light and continue the application towards 50 circles. At $1 \mathrm{~min}$ and $1 \mathrm{~min} 30$ after application, visually assess the Whiteness and the Glossiness of the residual film, respectively. At the end of $2 \mathrm{~min}$, evaluate the Greasiness of the residue by pinching 5 times the area where the product was applied. After each pinch, evaluate the Screech, by compressing the rest of the product between the index finger and the thumb."

The evaluation was performed in a sensory laboratory composed of individual booths, according to the NF EN ISO 8589. Each product sample was presented in a $5 \mathrm{ml}$ jar and identified with a randomly assigned threedigit code. Presentation order was randomly defined and changed for each session to reduce bias in evaluation.

The sensory methodology developed for the study of the nine emulsions was based on the perception of the product during and after application. It is an original methodology, never discussed for the Pickering emulsions before. The choice of the attributes for the evaluation was based on the differences between the products.

Seven discriminant attributes were evaluated consequently: three during (non-aqueous, difficulty of spreading, whitening effect) and four after the application of the product (film whiteness, glossiness, greasiness and the screech effect of the residue). Non-aqueous and difficulty of spreading are two key attributes particularly influenced by the composition of cosmetic emulsions [43-45]. Other attributes were selected according to the properties of the stabilising systems: whitening effect, film whiteness and screech residue related to the particle stabilised emulsions; film glossiness and greasiness related to the Steareth-2/21 containing emulsions.

\section{DATA ANALYSIS}

Results were presented as the mean value \pm standard deviation (SD).

XLSTAT software (Addinsoft, Paris, France) was used to perform the statistical analyses of the collected data. The ANOVA test (two-way analysis of variance) was applied to the results to spot the significant differences between the emulsions $(\mathrm{P}<0.05)$. Mean intensities were compared using the Tukey multiple comparison tests to distinguish different groups of products. Principal component analysis (PCA) was also performed on centred and autoscaled mean data to study the relationships between products and attributes. 


\section{RESULTS}

All the formulated systems were first analysed from the microscopic and macroscopic point of view to understand the mechanism of their formation, depending on the emulsifying system. Then, the textural properties of the nine emulsions were described by a panel of assessors during the sensory analysis. The obtained results will now be discussed.

\section{INDIVIDUAL PROPERTIES OF FORMULATED SYSTEMS}

First of all, the behaviour of the formulated samples was monitored over time for three temperatures of storage: $4^{\circ} \mathrm{C}$, ambient temperature and $40^{\circ} \mathrm{C}$. The samples were checked at D7, D15 and D30 by the microscopy, the particle size analysis and the rheology for the tree temperatures of the storage. No phenomena of destabilisation were observed over this time. The instrumental results that will be further presented were taken at the same time (D30) and at the same storage temperature (ambient temperature), as for the sensory analysis.

Considering the mechanism of the emulsion formation, it is interesting to notice that the $\mathrm{ZnO}$ containing emulsions are both of water in oil type (W/O), while the rest of the systems did orient the emulsion towards oil in water $(\mathrm{O} / \mathrm{W})$ organisation. Also, the microscopic organisation of the systems is remarkably different: the particle-stabilized emulsions form bigger oil droplets, while the Steareth-2/21 presence favours the formation of smaller oil droplets (Figure 1) as it could be expected according to the literature [46]. The complementary information about the physicochemical properties of $\mathrm{TiO}_{2}$ and/or Steareth-2/21 stabilised emulsions were given in our previous work [30].
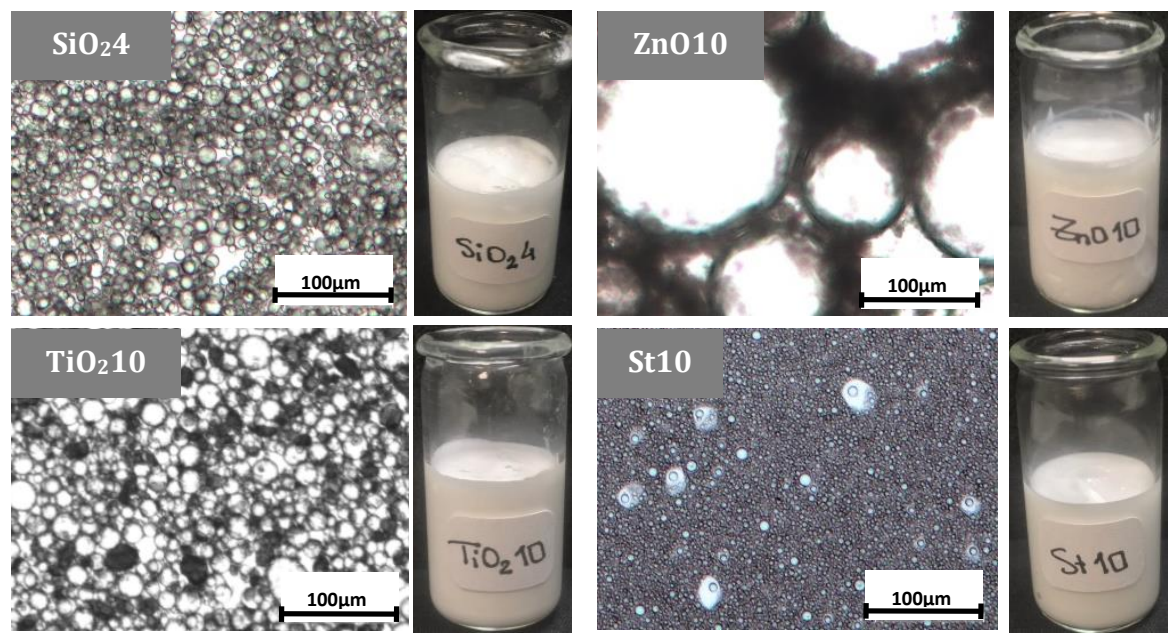

Figure 1. Microscopic organization of four studied emulsions: $\mathrm{SiO}_{2} 4, \mathrm{ZnO10}, \mathrm{TiO}_{2} 10$, St10 stored at the ambient temperature (D30) at x100 magnification, as well as a photography of homogenous and totally emulsified emulsions.

It is important to mention the specific properties of the $\mathrm{ZnO}$ containing emulsions. As it could be seen from Fig. 1, the droplet size of the Zn010 emulsion is extremely big, compared to the other systems. Moreover, the inverse water in oil emulsions stabilised by the $\mathrm{ZnO}$ are very fragile and the large droplets are immediately destroyed after even a weak solicitation. For this reason, the $\mathrm{ZnO}$ samples were the only ones not covered with the cover glass during the microscopic analysis due to immediate droplet destruction by this act. Consequently, one can expect a specific behaviour during the rheological investigation and the sensory application of these systems. 
Table IV. Emulsions type (water in oil for $\mathrm{W} / 0$ or oil in water for $0 / \mathrm{W}$ ) and $\mathrm{D}[4,3]$, the volume mean diameter, obtained by static light scattering measurements.

\begin{tabular}{|c|c|c|c|c|c|c|c|c|c|}
\hline Emulsion & $\begin{array}{l}\mathrm{ZnO10} \\
(\mathrm{W} / 0) \\
\end{array}$ & $\begin{array}{c}\text { Zn05St5 } \\
(\mathrm{W} / 0)\end{array}$ & $\begin{array}{l}\mathrm{TiO}_{2} 10 \\
(\mathrm{O} / \mathrm{W}) \\
\end{array}$ & $\begin{array}{l}\mathrm{TiO}_{2} 4 \\
(0 / W) \\
\end{array}$ & $\begin{array}{c}\mathrm{TiO}_{2} 5 \mathrm{St} 5 \\
(\mathrm{O} / \mathrm{W})\end{array}$ & $\begin{array}{l}\mathrm{SiO}_{2} 4 \\
(0 / \mathrm{W}) \\
\end{array}$ & $\begin{array}{c}\mathrm{SiO}_{2} 2 \mathrm{St} 2 \\
(0 / \mathrm{W})\end{array}$ & $\begin{array}{c}\text { St4 } \\
(0 / W)\end{array}$ & $\begin{array}{c}\text { St10 } \\
(0 / W)\end{array}$ \\
\hline $\begin{array}{c}\mathrm{D}[4,3] \\
\mu \mathrm{m}\end{array}$ & $1,11 \pm 0,02$ & $29,78 \pm 3,06$ & $12,92 \pm 0,33$ & $27,07 \pm 1,44$ & $3,28 \pm 0,38$ & $9,53 \pm 0,76$ & $5,68 \pm 0,18$ & $2,01 \pm 0,03$ & $1,74 \pm 0,03$ \\
\hline
\end{tabular}

The $\mathrm{D}[4,3]$ values also show the fragility of the Zn010 system (Table IV). The obtained values equal to $1 \mu \mathrm{m}$ demonstrates that the droplets seen on the micrographs are destroyed even by the dilution of the sample.

The dynamic viscosity values at the $1 \mathrm{~s}^{-1}$ shear rate for each emulsion are given in Table $\mathbf{V}$. The important differences between the registered values are pointing at the fact that the stabilising system also affects the macroscopic organisation of the emulsion. For example, at the same particle concentration, $\mathrm{SiO}_{2} 4$ emulsion is thirty times more viscous than $\mathrm{TiO}_{2} 4$ and it may be due to the system's gelation by silica particles [7].

Table V. Dynamic viscosities values at $1 \mathrm{~s}^{-1}$ shear rate for the samples stored at the ambient temperature at D30.

\begin{tabular}{cccccccccc}
\hline Emulsion & $\mathbf{Z n 0 1 0}$ & $\mathbf{Z n O 5 S t 5}$ & $\mathbf{T i O}_{2} \mathbf{1 0}$ & $\mathbf{T i O}_{2} 4$ & $\mathbf{T i O}_{2} 5 S t 5$ & $\mathbf{S i O}_{2} 4$ & $\mathbf{S i O}_{2} 2 S t 2$ & St4 & St10 \\
\hline $\begin{array}{c}\text { Viscosity at 1s } \\
\text { (Pa.s) }\end{array}$ & $30,90 \pm 1,22$ & $21,09 \pm 2,04$ & $26,62 \pm 0,04$ & $9,46 \pm 0,31$ & $15,35 \pm 0,52$ & $276,11 \pm 8,47$ & $6,94 \pm 0,21$ & $4,79 \pm 0,05$ & $35,29 \pm 1,04$ \\
\hline
\end{tabular}

Microscopic and macroscopic variations between the obtained emulsions suggest that the texture of the systems will be differently perceived by the assessors.

\section{SENSORY PROPERTIES OF PICKERING EMULSIONS COMPARED TO CONVENTIONAL SYSTEMS}

The main purpose of the sensory analysis was to draw the sensory profile of Pickering emulsions. A conventional surfactant Steareth-2/Steareth-21 was used at $4 \%$ and $10 \%$ for the formulation of the references at the same concentration in stabilizer as for the Pickering emulsions. Two groups will be discussed hereafter: containing $4 \%$ of emulsifier $\left(\mathrm{SiO}_{2} 4, \mathrm{TiO}_{2} 4\right.$ and the St4 reference) and containing $10 \%$ of emulsifier $(\mathrm{ZnO} 010$, $\left.\mathrm{TiO}_{2} 10, \mathrm{St10}\right)$.

\section{COMPARISON OF THREE SYSTEMS CONTAINING $4 \%$ OF THE EMULSIFIER}

Two Pickering and one conventional emulsion were compared on the scale between 0 and 9 (Figure 2). The important SD for the obtained results are usual for the sensory analysis inherent to differences in assessors evaluation [26-29]. Despite the identic water quantity in all the samples, the panel could statistically discriminate the products. $\mathrm{TiO}_{2} 4$ emulsion was perceived as the most aqueous (0.8), approaching the pure water value. Moreover, it was also scored as easy to spread (1.6), with an important whitening effect (4.1) and film whiteness (3.0) when compared to two other systems. It is interesting to notice that for these three attributes (difficulty of spreading, whitening effect and film whiteness), the panel could not notice any important difference between $\mathrm{SiO}_{2} 4$ and $\mathrm{St} 4$, stabilised by extremely different emulsifiers. The differences between both systems are more significant for the final properties of the film: the silica particles could reduce the film glossiness (2.6) and greasiness (2.1), compared to Steareth-2/21 emulsion. Finally, the panel could specifically designate the particle-containing emulsions through their low greasiness and their screech residue properties. 


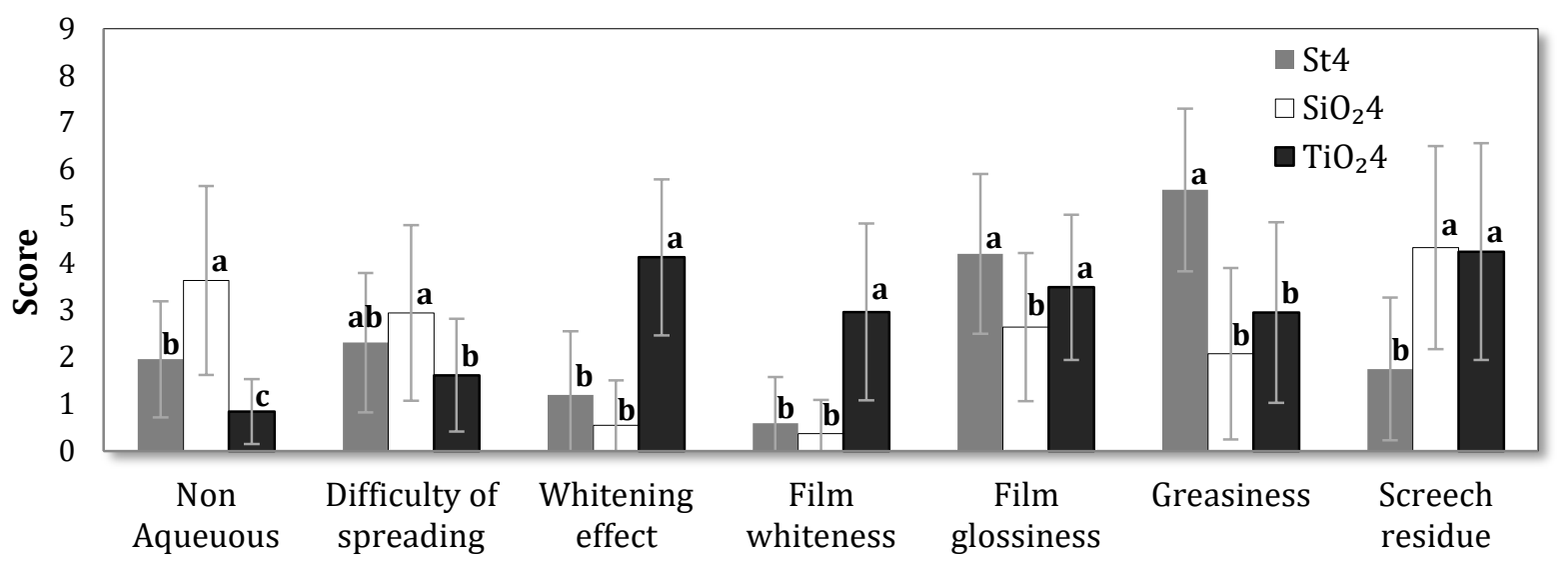

Figure 2. The average score and the standard deviation obtained by $\mathrm{St} 4, \mathrm{SiO}_{2} 4$ and $\mathrm{TiO}_{2} 4$ emulsions for each of the seven studied attributes. a-c Values with a different letter for each attribute indicate that corresponding products are significantly different $(\mathrm{P}<0.05)$.

\section{COMPARISON OF THREE SYSTEMS CONTAINING $10 \%$ OF THE EMULSIFIER}

The perception of the systems containing $10 \%$ of the emulsifying system is more pronounced than for $4 \%$. In Figure 3, two Pickering emulsions stabilised by $10 \%$ of $\mathrm{TiO}_{2}(\mathrm{O} / \mathrm{W})$ and $\mathrm{ZnO}$ are compared with a conventional emulsion containing $10 \%$ of Steareth $2 / 21$ emulsifier.

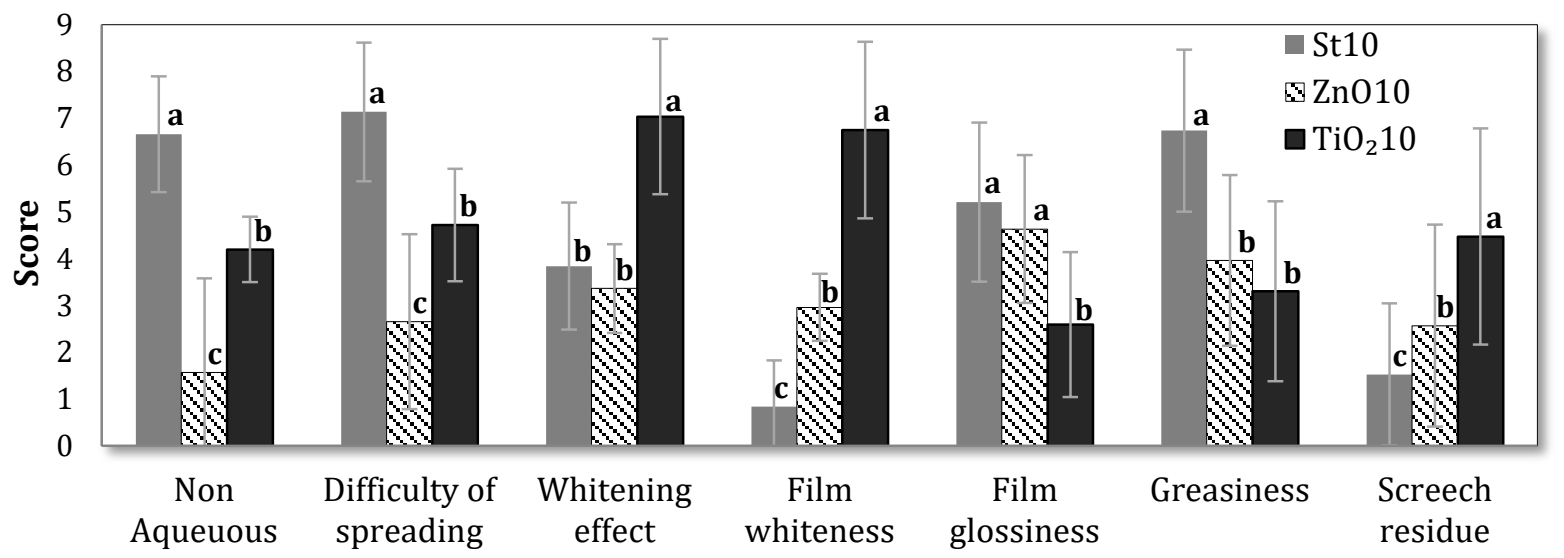

Figure 3. The average score and the standard deviation obtained by $\mathrm{St10}_{10} \mathrm{ZnO10}$ and $\mathrm{TiO}_{2} 10$ emulsions for each of the seven studied attributes. a-c Values with a different letter for each attribute indicate that corresponding products are significantly different $(\mathrm{P}<0.05)$.

The St10 emulsion was considered as the least aqueous and the most difficult to spread, followed by $\mathrm{TiO}_{2} 10$ and, finally, by the Zn010 emulsions. One can notice that the judges could not differentiate St10 from Zn010 for the whitening effect attribute during the application, due to the "soap" effect of the Steareth-2/21 surfactant at a high amount. During the penetration, this effect disappears for the St10 emulsion, while the $\mathrm{ZnO}$ particles on the surface of the skin increase the score for the film whiteness. $\mathrm{The}^{\mathrm{TiO}} \mathrm{P}_{2}$ particles at $10 \%$, with an important whitening effect, mitigate the film glossiness and greasiness. Even though two Pickering emulsions contain the same quantity of particles, the screech of the residue is more pronounced for the titanium dioxide particles. 


\section{THE PARTICLE EFFECT}

Since conventional surfactants and particles are able to stabilise the oil/water interface and to totally emulsify both phases, it is interesting to observe the role of each type of stabilising system in a mixture of both. For this purpose, the silicon dioxide/titanium dioxide/zinc oxide particles were formulated together with the Steareth-2/21 surfactant. Three systems are here compared containing $0 \% / 100 \%, 50 \% / 50 \%, 100 \% / 0 \%$ of surfactant/particles mixture.

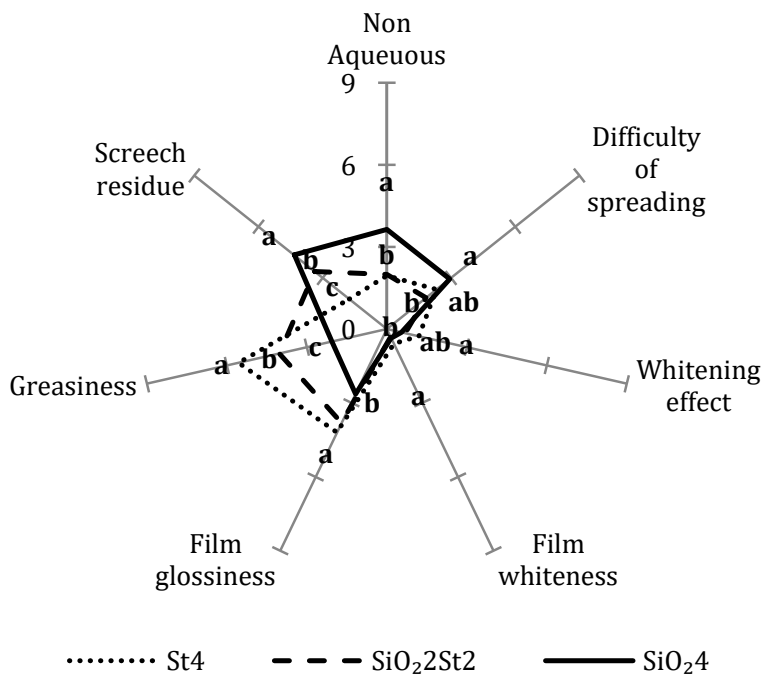

Figure 4. Comparison of $\mathrm{St} 4, \mathrm{SiO}_{2} 2 \mathrm{St} 2, \mathrm{SiO}_{2} 4$ emulsions over seven studied attributes. a-c Values with a different letter for each attribute indicate that corresponding products are significantly different $(P<0.05)$.

Steareth-2/21 4\% emulsion is compared with the emulsion stabilised by the mixture Steareth-2/21 $2 \% \mathrm{SiO}_{2} 2 \%$ and with $\mathrm{SiO}_{2} 4$ (Figure 4). For the difficulty of spreading, the whitening effect and the film whiteness, the three emulsions are statistically similar. However, it is interesting to notice that adding the silicon dioxide particles to the conventional surfactant reduces the greasiness (4.0) of the residue and slightly the film glossiness (3.8), while the $\mathrm{SiO}_{2} 4$ emulsion shows the lowest values for these attributes (greasiness - 2.1, film glossiness -2.6 ), pointing at its capacity to reduce the "fatty" perception.

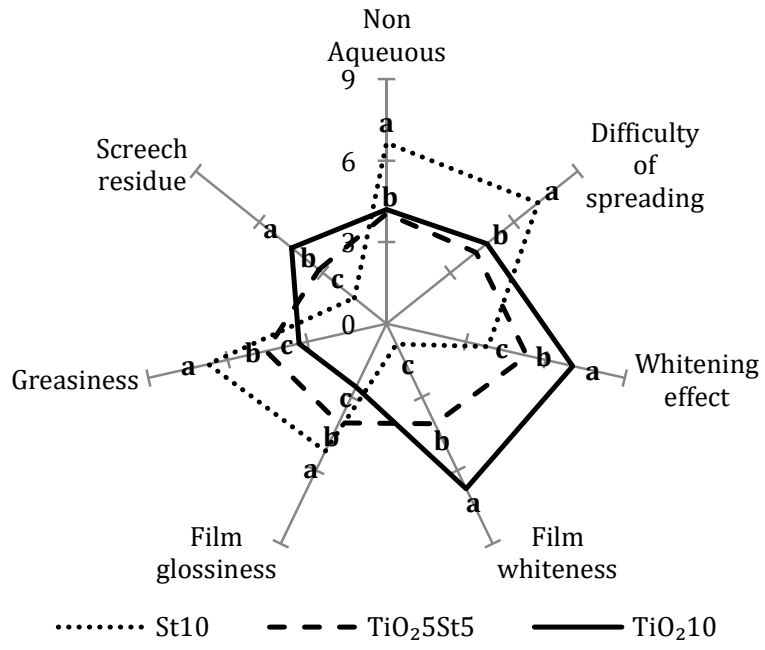

Figure 5. Comparison of St10, $\mathrm{TiO}_{2} 5 \mathrm{St5}, \mathrm{TiO}_{2} 10$ emulsions over seven studied attributes. a-c Values with a different letter for each attribute indicate that corresponding products are significantly different $(P<0.05)$. 
Graphical representation of $\mathrm{St} 10, \mathrm{TiO}_{2} 5 \mathrm{St} 5, \mathrm{TiO}_{2} 10$ emulsions in Figure 5 illustrates an important divergence of the scores between the products. The use of the titanium dioxide particles alone or together with the Steareth-2/21 surfactant induces the formation of the emulsions perceived as less aqueous and less difficult to spread. As expected, the whitening effect and the film whiteness, as well as the screech of the residue are gradually intensified when the particle quantity increase in the emulsion, while the gloss and the grease effect of the residue are reduced. The use of the $\mathrm{TiO}_{2}$ at $5 \%$ and of Steareth-2/21 at $5 \%$ as the emulsifying system permits to obtain intermediate scores for the studied attributes.

Meanwhile, the situation is quite different for zinc oxide. As it could be seen from Figure 6, both emulsions containing $\mathrm{ZnO}$ are aqueous and easy to spread, contrary to the conventional emulsion. ZnO10 can be only discriminated from the other systems for the film whiteness (3.0) and the screech residue (2.6) attributes, due to the important quantity of solid particles. The film glossiness is not impacted by the emulsion composition, only the greasiness of the Steareth-2/21 is constantly more important due to the intrinsic surfactant properties.

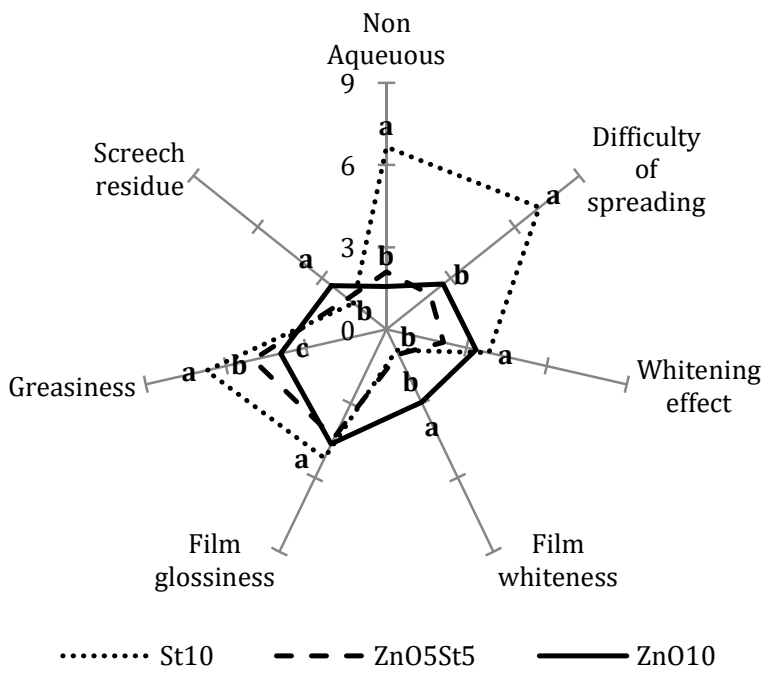

Figure 6. Comparison of St10, Zn05St5, Zn010 emulsions over seven studied attributes. a-c Values with a different letter for each attribute indicate that corresponding products are significantly different $(\mathrm{P}<0.05)$.

\section{DISCUSSION}

The aim of this study was to describe the textural properties of Pickering emulsions compared to the properties of conventional formulations.

It is known that the surfactant is an amphiphilic molecule able to reduce the oil/water interfacial tension and it forms an electrostatic and steric barrier at the interface between two liquids [47]. Meanwhile, due to the partial wetting of the surface of the solid particles by water and oil [12,48], particle stabilisation is an anchoring of solid particles at the oil-water interface, creating a barrier against coalescence $[49,50]$. One should consider the differences in the formation mechanism of surfactant-stabilised and particle-stabilised emulsions, which clearly impact the sensory perception of the formulas.

The first purpose of the study was to obtain stable, totally emulsified systems. Three different particles were selected: Titanium Dioxide coated with Silica and Cetyl Phosphate (at 4\% and 10\%); Zinc oxide coated with 
Jojoba Esters (at 10\%) and finally Silica Cetyl Silylate (at 4\%). Each particle could efficiently stabilise the interface and integrally emulsify both phases, with no creaming or drainage destabilisation over time. The retained quantities of solid particles were optimal for the formation of the stable system: $\mathrm{TiO}_{2}$ can stabilise at $4 \%$ and $10 \%$ in the emulsion, $\mathrm{ZnO}$ is efficient only at $10 \%$, while $\mathrm{SiO}_{2}$ at more than $4 \%$ is forming too consistent emulsions.

The micro and macrostructure of the emulsions are strongly affected by the emulsifying system (Figure 1 and Table V), and, as a consequence, the sensory perception is also influenced. According to diverse studies, the difficulty of spreading attribute is related to the emulsion consistency: less consistent emulsion is easier to be spread [51-53]. These results are coherent with the Steareth-2/21 emulsions. But, unlike the literature examples, the emulsions stabilised by solid particles do not demonstrate this behaviour. Each particle showed the individual effect on this attribute: $\mathrm{TiO}_{2}$ containing emulsions, being less viscous than $\mathrm{St10}$, are still difficult to spread, followed by $\mathrm{ZnO}$ (Figure 3). Meanwhile, the $\mathrm{SiO}_{2} 4 \%$ emulsion, clearly shows high viscosity value for the rheology test (Table V), due to the silica gel formation in the continuous phase, but is considered as easy to spread by the sensory panel (Figure 2). For this reason, the emulsions containing or stabilised by the solid particles are different from conventional emulsions, as proved by previous results.

The sensory analysis allowed the classification of the studied emulsions as a function of the seven attributes, which is graphically represented, thought a PCA (Principal Component Analysis) in Figure 7.
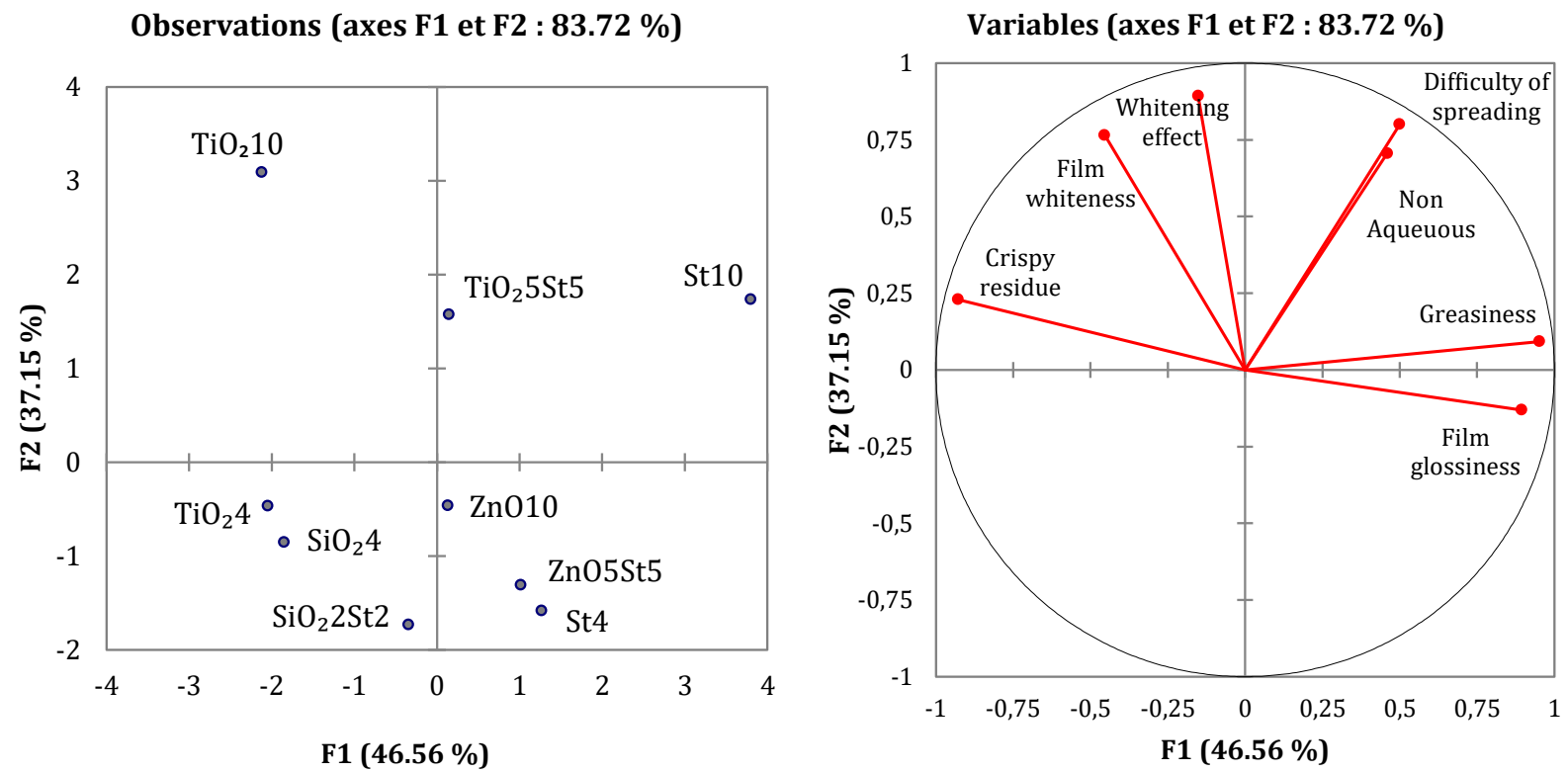

Figure 7. Graphic representation of Principal Component Analysis (PCA) of the products (on the left) and the correlation circle of the attributes (on the right).

The titanium dioxide containing emulsions are highly governed by the particle presence: the whitening effect during and after application (due to an important refractive index of the $\mathrm{TiO}_{2} \leq 4$ [54]), as well as the screech residue, prevail for the $\mathrm{TiO}_{2} 10$ emulsion, followed by $\mathrm{TiO}_{2} 5 \mathrm{St} 5$ and $\mathrm{TiO}_{2} 4$. It is obvious that the particle quantity, more than the emulsion organisation, will affect these three attributes. However, the presence of Steareth-2/21 in $\mathrm{TiO}_{2} 5 \mathrm{St} 5$ inclines its properties towards more "fatty" perception.

It is interesting to notice that the Silica Cetyl Silylate containing emulsions are nearly identic over the F2 axe. $\mathrm{SiO}_{2} 4, \mathrm{SiO}_{2} 2 \mathrm{St} 2$ and $\mathrm{St} 4$ emulsions were more distinguished over $\mathrm{F} 1$ axe: screech residue, highly pronounced 
for the silica at $4 \%$, is reduced with silica decrease and the Steareth-2/21 addition to the system, while the residue becomes glossy and greasy.

For the common oil in water emulsions, the aqueous perception is related to the water quantity of the system and the ability of the surfactant to organise itself in different liquid crystal shapes, affecting the water retention and perception. Considering the water in oil, $\mathrm{ZnO}$ containing emulsions, the results were quite unexpected. Despite the high concentration (10\%) of metal oxides in ZnO10 emulsion, its whitening effect and the screech of the residue is surprisingly lower than for $\mathrm{TiO}_{2} 10$ emulsion. Moreover, the water liberation during the spreading of the product so-called "quick breaking" effect [55], made the panel perceive the $\mathrm{ZnO}$ emulsions as aqueous, even at $10 \%$ of the emulsifying system.

For the particles/Steareth-2/21 mixture, the behaviour is intermediate. From the sensory perception, no matter which system plays the main role in the stabilisation process, the applicative properties and the final residue evolve gradually, depending on the emulsion composition: for the particle stabilised systems, the metal oxide governs the final perception. The addition of Steareth-2/21 with long carbon chains contributes to the increase of the "fatty" after-feeling of the emulsions.

\section{CONCLUSION}

The present work focused on the sensory analysis of Pickering emulsions, stabilised by three types of solid particles: titanium dioxide, (coated with Silica and Cetyl Phosphate), Zinc oxide (coated with Jojoba esters) and Silica Cetyl Silylate. The same particles were used to formulate 50/50 particle/Steareth-2/21 emulsions. Finally, two emulsifier-stabilised emulsions served as references in this study.

The sensory perception is strongly affected by the type of the metal oxide: the $\mathrm{SiO}_{2}$ particles form emulsion sufficiently similar to one stabilised by a conventional surfactant used for the study. Undoubtedly, the presence of the particles at $4 \%$ increased the screech of the residue, while the Steareth- $2 / 21$ emulsion at $4 \%$ was perceived as more greasy and glossy. But the differences are less pronounces that in case of other metal oxides. For $\mathrm{TiO}_{2}$, the sensory profile is quite different from the emulsion stabilised by the Steareth-2/21 surfactant, the mixture of them assuring the intermediate properties. The presence of this metal oxide amplifies the whitening effect and the screech of the residue. Finally, the $\mathrm{ZnO}$ containing emulsion, alone or in combination with the surfactant, is quite different from the classic one. The $\mathrm{ZnO}$ particles oriented the emulsion towards the water in oil organisation. In other words, the $\mathrm{ZnO}$ Pickering emulsion and the $\mathrm{ZnO} /$ Steareth-2/21 mixture will be similarly perceived, the small difference is only observed for the film whiteness and the screech of the residue, which is directly linked to the particle quantity in the emulsion.

Considering the emulsions stabilised by both systems, particles and surfactant, it was demonstrated that from the sensory point of view, there is no concurrence between the stabilising systems. The sensory attributes are more affected by the number of initial ingredients, metal oxides or emulsifier. The present study also showed that the metal oxides regulate the emulsions orientation $(0 / \mathrm{W}$ or $\mathrm{W} / 0)$, which will change the emulsion perception, depending on which phase will interact first with the skin. Meanwhile, the particles used for the emulsion formulation will directly affect the properties of the residual film, after the emulsion's penetration.

This research brings novelty in the non-studied field of the sensory profile of Pickering emulsions. It gives detailed information about the impact of solid particles on the textural properties of cosmetic emulsions. A good perspective of this work will be the demonstration of the fact that the sensory profile is not only directly governed by the properties of the particles, but also indirectly. Through a combination of microscopic and macroscopic techniques, it will be interesting to show that the particles possess a capacity to form a droplet network and also to organise the external phase. These parameters will impact the spreading properties and the aqueous feeling of the formulations. 


\section{DECLARATIONS OF INTEREST}

None.

\section{BIBLIOGRAPHY}

[1] Pickering SU. CXCVI.-Emulsions. J. Chem. Soc. Trans., 91, 2001-21 (1907).

[2] Binks BP. Colloidal Particles at Liquid Interfaces. Cambridge University Press, (2006).

[3] Yang Y, Fang Z, Chen X, Zhang W, Xie Y, Chen Y, Liu Z, Yuan W. An Overview of Pickering Emulsions: Solid-Particle Materials, Classification, Morphology, and Applications. Front. Pharmacol., 8, (2017).

[4] Marto J, Pinto P, Fitas M, Gonçalves LM, Almeida AJ, Ribeiro HM. Safety assessment of starch-based personal care products: Nanocapsules and pickering emulsions. Toxicol. Appl. Pharmacol., 342, 14-21 (2018).

[5] Udoetok I, D. Wilson L, Headley J. Stabilization of Pickering Emulsions by Iron oxide Nano-particles. J. Adv. Mater. Sci., 1, (2016).

[6] Stiller S, Gers-Barlag H, Lergenmueller M, Pflücker F, Schulz J, Wittern KP, Daniels R. Investigation of the stability in emulsions stabilized with different surface modified titanium dioxides. Colloids Surf. Physicochem. Eng. Asp., 232, 261-7 (2004).

[7] Torres LG, Iturbe R, Snowden MJ, Chowdhry BZ, Leharne SA. Preparation of o/w emulsions stabilized by solid particles and their characterization by oscillatory rheology. Colloids Surf. Physicochem. Eng. Asp., 302, 439-48 (2007).

[8] Binks BP, Yin D. Pickering emulsions stabilized by hydrophilic nanoparticles: in situ surface modification by oil. Soft Matter, 12, 6858-67 (2016).

[9] Frelichowska J, Bolzinger M-A, Pelletier J, Valour J-P, Chevalier Y. Topical delivery of lipophilic drugs from o/w Pickering emulsions. Int. J. Pharm., 371, 56-63 (2009).

[10] Arditty S, Whitby CP, Binks BP, Schmitt V, Leal-Calderon F. Some general features of limited coalescence in solid-stabilized emulsions. Eur. Phys. J. E, 11, 273-81 (2003).

[11] Binks BP. Particles as surfactants-similarities and differences. Curr. Opin. Colloid Interface Sci., 7, 21-41 (2002).

[12] Aveyard R, Binks BP, Clint JH. Emulsions stabilised solely by colloidal particles. Adv. Colloid Interface Sci., 100-102, 503-46 (2003).

[13] McClements DJ. Context and background. Food Emulsions: Principles, Practices, and Techniques, Second Edition. CRC Press, pp.1-26 (2004).

[14] Binks BP, Lumsdon SO. Influence of Particle Wettability on the Type and Stability of Surfactant-Free Emulsions. Langmuir, 16, 8622-31 (2000).

[15] Hong JS, Fischer P. Bulk and interfacial rheology of emulsions stabilized with clay particles. Colloids Surf. Physicochem. Eng. Asp., 508, 316-26 (2016).

[16] Kargar M, Spyropoulos F, Norton IanT. The effect of interfacial microstructure on the lipid oxidation stability of oil-in-water emulsions. J. Colloid Interface Sci., 357, 527-33 (2011).

[17] Harman CLG, Patel MA, Guldin S, Davies G-L. Recent developments in Pickering emulsions for biomedical applications. Curr. Opin. Colloid Interface Sci., 39, 173-89 (2019).

[18] Tikekar RV, Pan Y, Nitin N. Fate of curcumin encapsulated in silica nanoparticle stabilized Pickering emulsion during storage and simulated digestion. Food Res. Int., 51, 370-7 (2013).

[19] Wang MS, Chaudhari A, Pan Y, Young S, Nitin N. Controlled Release of Natural Polyphenols in Oral Cavity Using Starch Pickering Emulsion. MRS Online Proc. Libr. Arch., 1688, (2014).

[20] Marto J, Gouveia L, Jorge IM, Duarte A, Gonçalves LM, Silva SMC, Antunes F, Pais AACC, Oliveira E, Almeida AJ, Ribeiro HM. Starch-based Pickering emulsions for topical drug delivery: A QbD approach. Colloids Surf. B Biointerfaces, 135, 183-92 (2015).

[21] Marku D, Wahlgren M, Rayner M, Sjöö M, Timgren A. Characterization of starch Pickering emulsions for potential applications in topical formulations. Int. J. Pharm., 428, 1-7 (2012).

[22] Simovic S, Ghouchi-Eskandar N, Prestidge CA. Pickering emulsions for dermal delivery. J. Drug Deliv. Sci. Technol., 21, 123-33 (2011).

[23] Frelichowska J, Bolzinger M-A, Valour J-P, Mouaziz H, Pelletier J, Chevalier Y. Pickering w/o emulsions: Drug release and topical delivery. Int. J. Pharm., 368, 7-15 (2009). 
[24] Moravkova T, Filip P. Relation between sensory analysis and rheology of body lotions. Int. J. Cosmet. Sci., 38, 558-66 (2016).

[25] Morávková T, Stern P. Rheological and textural properties of cosmetic emulsions. Appl. Rheol., 21, (2011).

[26] Gilbert L, Picard C, Savary G, Grisel M. Impact of Polymers on Texture Properties of Cosmetic Emulsions: A Methodological Approach. J. Sens. Stud., 27, 392-402 (2012).

[27] Dubuisson P, Picard C, Grisel M, Savary G. How does composition influence the texture of cosmetic emulsions? Colloids Surf. Physicochem. Eng. Asp., (2017).

[28] Terescenco D, Savary G, Picard C, Clemenceau F, Merat E, Grisel M. Influence of the emollient on emulsions containing lamellar liquid crystals: from molecular organization towards applicative properties. Int. J. Cosmet. Sci., 40, 565-74.

[29] Savary G, Gilbert L, Grisel M, Picard C. Instrumental and sensory methodologies to characterize the residual film of topical products applied to skin. Skin Res. Technol., 25, 415-23 (2019).

[30] Terescenco D, Hucher N, Savary G, Picard C. From interface towards organised network: questioning the role of the droplets arrangements in macroscopically stable 0/W emulsions composed of a conventional non-ionic surfactant, TiO2 particles, or their mixture. Colloids Surf. Physicochem. Eng. Asp., 123630 (2019).

[31] Frelichowska J, Bolzinger M-A, Pelletier J, Valour J-P, Chevalier Y. Skin Penetration from Pickering Emulsions. Advances in Dermatological Sciences. pp.124-42 (2013).

[32] Wang SQ, Tooley IR. Photoprotection in the era of nanotechnology. Semin. Cutan. Med. Surg., 30, 210-3 (2011).

[33] Marto J, Ascenso A, Gonçalves LM, Gouveia LF, Manteigas P, Pinto P, Oliveira E, Almeida AJ, Ribeiro HM. Melatonin-based pickering emulsion for skin's photoprotection. Drug Deliv., 23, 1594-607 (2016).

[34] Marto J, Gouveia LF, Chiari BG, Paiva A, Isaac V, Pinto P, Simões P, Almeida AJ, Ribeiro HM. The green generation of sunscreens: Using coffee industrial sub-products. Ind. Crops Prod., 80, 93-100 (2016).

[35] Marto J, Gouveia LF, Gonçalves L, Chiari-Andréo BG, Isaac V, Pinto P, Oliveira E, Almeida AJ, Ribeiro HM. Design of novel starch-based Pickering emulsions as platforms for skin photoprotection. J. Photochem. Photobiol. B, 162, 56-64 (2016).

[36] Schröder A, Corstens MN, Ho KKHY, Schroën K, Berton-Carabin CC. Pickering Emulsions. Emulsion-based Systems for Delivery of Food Active Compounds. John Wiley \& Sons, Ltd, pp.29-67 (2018).

[37] Ash M. Handbook of Green Chemicals. Synapse Info Resources, (2004).

[38] Pasquali RC, Taurozzi MP, Sacco N, Bregni C. Birefringent emulsions stabilized with steareth-2 and steareth-21. Lat. Am. J. Pharm., 27, 839-44 (2008).

[39] Rossano M, Hucher N, Picard C, Colletta D, Le Foll F, Grisel M. Effects of aging on structure and stability of TiO2 nanoparticle-containing oil-in-water emulsions. Int. J. Pharm., 461, 89-96 (2014).

[40] Rowenczyk L, Picard C, Duclairoir-Poc C, Hucher N, Orange N, Feuilloley M, Grisel M. Development of preservative-free nanoparticles-based emulsions: Effects of NP surface properties and sterilization process. Int. J. Pharm., 510, 125-34 (2016).

[41] AFNOR. NF EN ISO 21149. Cosmétiques- Microbiologie - Dénombrement et détection des bactéries aérobies mésophiles, 2017.

[42] AFNOR. NF EN ISO 16212. Cosmétiques - Microbiologie - Dénombrement des levures et des moisissures, 2017.

[43] ASTM E1490-92(1997). Standard Practice for Descriptive Skinfeel Analysis of Creams and Lotions. ASTM International, West Conshohocken, PA, (1997).

[44] Lee I-S, Yang H-M, Kim J-W, Maeng Y-J, Lee C-W, Kang Y-S, Rang M-J, Kim H-Y. Terminology Development and Panel Training for Sensory Evaluation of Skin Care Products Including Aqua Cream. J. Sens. Stud., 20, 421-33 (2005).

[45] Meilgaard MC, Carr BT, Civille GV. The Spectrum Descriptive Analysis Method. Sensory Evaluation Techniques, Fourth Edition. CRC Press, pp.189-253 (2006).

[46] Binks BP, Rodrigues JA, Frith WJ. Synergistic Interaction in Emulsions Stabilized by a Mixture of Silica Nanoparticles and Cationic Surfactant. Langmuir, 23, 3626-36 (2007).

[47] Rosen MJ, Kunjappu JT. Surfactants and Interfacial Phenomena. John Wiley \& Sons, (2012).

[48] Chevalier Y, Bolzinger M-A. Emulsions stabilized with solid nanoparticles: Pickering emulsions. Colloids Surf. Physicochem. Eng. Asp., 439, 23-34 (2013). 
[49] Menon VB, Wasan DT. Characterization of oil-water interfaces containing finely divided solids with applications to the coalescence of water-in-oil Emulsions: A review. Colloids Surf., 29, 7-27 (1988).

[50] Tambe DE, Sharma MM. Factors Controlling the Stability of Colloid-Stabilized Emulsions: I. An Experimental Investigation. J. Colloid Interface Sci., 157, 244-53 (1993).

[51] Guest S, McGlone F, Hopkinson A, Schendel ZA, Blot K, Essick G. Perceptual and Sensory-Functional Consequences of Skin Care Products. J. Cosmet. Dermatol. Sci. Appl., 3, 720-6 (2013).

[52] Douguet M, Picard C, Savary G, Merlaud F, Loubat-bouleuc N, Grisel M. Spreading properties of cosmetic emollients: Use of synthetic skin surface to elucidate structural effect. Colloids Surf. B Biointerfaces, 154, 307-14 (2017).

[53] Gore E, Picard C, Savary G. Spreading behavior of cosmetic emulsions: Impact of the oil phase. Biotribology, 16, 17-24 (2018).

[54] Tanemura S, Miao L, Wunderlich W, Tanemura M, Mori Y, Toh S, Kaneko K. Fabrication and characterization of anatase/rutile-TiO2 thin films by magnetron sputtering: a review. Sci. Technol. Adv. Mater., 6, 11-7 (2005).

[55] Ratschow C, Meyer C, Hagens R, Scheede S, Ratschow C, Meyer C, Hagens R, Scheede S. W02014090615A3 (2015). 